Check for updates

\title{
Mechanical Performance of a Self- Unplugging Surgical Suction Instrument: A Randomized Controlled Trial
}

James B. Stiehl, M.D.

\begin{abstract}
Introduction: Obstruction of the surgical suction instrument is a common problem in orthopaedic surgery. Previous attempts have tried to address this problem. The 'Super Sucker' has a screen compartment that can be unclogged upon disassembly. The Yankauer sucker has small holes in its tip that strain larger bits of debris. The aim of this study is to clinically evaluate a new gas-actuated suction instrument in which a special screen at its tip is cleared, as needed, by a rapid burst of pressurized carbon dioxide gas.

Methods: This IRB-approved, prospective, randomized study compared a gas-actuated suction instrument with the Super Sucker and Yankauer in 70 consecutive primary total joint arthroplasty cases. Outcome measures included: incidence of complete suction loss due to suction instrument obstruction; time lost while unplugging the suction instrument; number of additional suction instruments needed; and a subjective surgeon-assessed performance score ( 1 to 5 , with 5 being most favorable) for type of suction instrument.

Results: There were no cases in which the gas-actuated suction instrument could not be rapidly cleared of debris. The Super Sucker completely plugged in $71 \%$ of cases, requiring 67 minutes total to unplug (3.9 minutes per case, range 0 to 12 minutes). In four cases, replacement Super Suckers were required to finish the case. The Yankauer completely plugged in $47 \%$ of cases, requiring 52 minutes total to unplug (2.8 minutes per case, range 0 to 10 minutes). In three cases, replacement Yankauers were required to finish the case. The average performance score was 2.7 for the Super Sucker, 3.6 for the Yankauer, and 5 for the gas-actuated suction instrument on a scale of 1 to 5, with 5 being most favorable.

Discussion: This study evaluated a suction instrument in which a screen tip prevents obstruction, and a burst of pressurized carbon dioxide gas clears debris from the tip. The new suction instrument was successful in $100 \%$ of cases, with considerably less time lost compared to the other suction instruments. The gas-actuated suction tool actively and rapidly cleared obstructive debris with minimal disruption to the surgical flow. Recent clinical experience has shown the gas-actuated suction tool to be particularly enabling in the settings of tourniquet-free total knee replacement, small incision total hip replacement, bipolar hemiarthroplasty, and revision total hip replacement.
\end{abstract}

Keywords: suction, total joint arthroplasty, tourniquet-less, carbon dioxide gas

$\S$ St Mary's Hospital

400 N. Pleasant Ave., Centralia, Illinois 62801

Copyright 2014, James B. Stiehl. All rights reserved.

JISRF gives permission for reproduction of articles as long as notification and recognition is provided. 


\section{Introduction}

For generations, modern surgical technique has utilized the ability of operating room vacuum systems to create suction as a method of evacuating fluids and debris from a surgical field. This problem is no more manifest than in orthopaedic surgery, where a fundamental principle in the treatment of surgical wounds is to flush the tissue with high volumes of sterile antibiotic-loaded fluid to reduce bacterial contamination. An important technical issue for the removal of fluids is the ability to maintain an unobstructed flow of suction. Plugging of the suction instrument is a source of irritation and delay for orthopaedic surgeons all over the world who deal with the typical suction instrument that becomes chronically plugged due to small fragments of bone and soft tissue. This debris is created during surgical manipulations and can become lodged in the tip, internal chamber, or tubing of the suction instrument (Figure 1). A number of systems have been designed over the years to deal with this problem. One such device, known as the 'Super Sucker' (Gateway Medical, Mooresville, NC, USA), utilizes a modular plastic device that has a tubular screen in the proximal part that, once plugged, allows the surgeon to disassemble the device, clean off the screen, reassemble the device, and resume the operation. [7] This maneuver can be required 4 to 5 times during a standard orthopaedic procedure. In addition, the suction tubing may become clogged by a chunk of bone that becomes lodged at one of its internal junctions.

This study evaluates the performance of a new surgical suction instrument that is designed to be self-unplugging via a mechanically activated jet of carbon dioxide (CO2) gas. The tip of the instrument contains a porous metal screen that is intended to capture solid and viscous material that has been liberated from a surgical wound. The pores in the screen tip are a fraction of the inner tubing di-

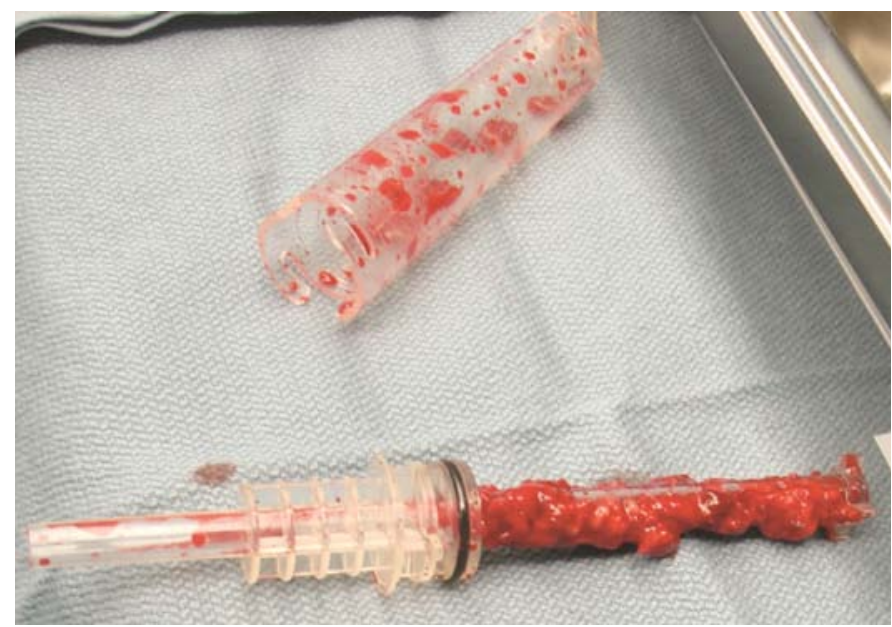

Figure 1. Discarded 'Super Sucker' that clogged during primary TKA; Obstruction is a relatively common occurrence. ameter, thus preventing large chunks of bone from moving up the tube and becoming lodged. A porous metal screen was found to be more effective than a wire mesh screen, as the porous metal screen could easily be wiped of debris, much as a spaghetti strainer. The suction instrument also includes a long thin tube that is placed inside the suction conduit for delivery of a positive pressure carbon dioxide $(\mathrm{CO} 2)$ gas jet to the back side of the screen. The effect of this internal gas jet is to 'blast' debris off of the tip as needed (Figures 2A and 2B). The hypothesis of this study was that the gas-actuated suction instrument would be less likely to plug during a typical orthopaedic procedure such as a total joint arthroplasty (TJA). A randomized control trial was designed to test the hypothesis against two commonly used suction instruments, the Yankauer and the Super Sucker. [7,10]

\section{Methods}

This study is an IRB-approved, single-blinded, randomized controlled trial. Patients were recruited from the
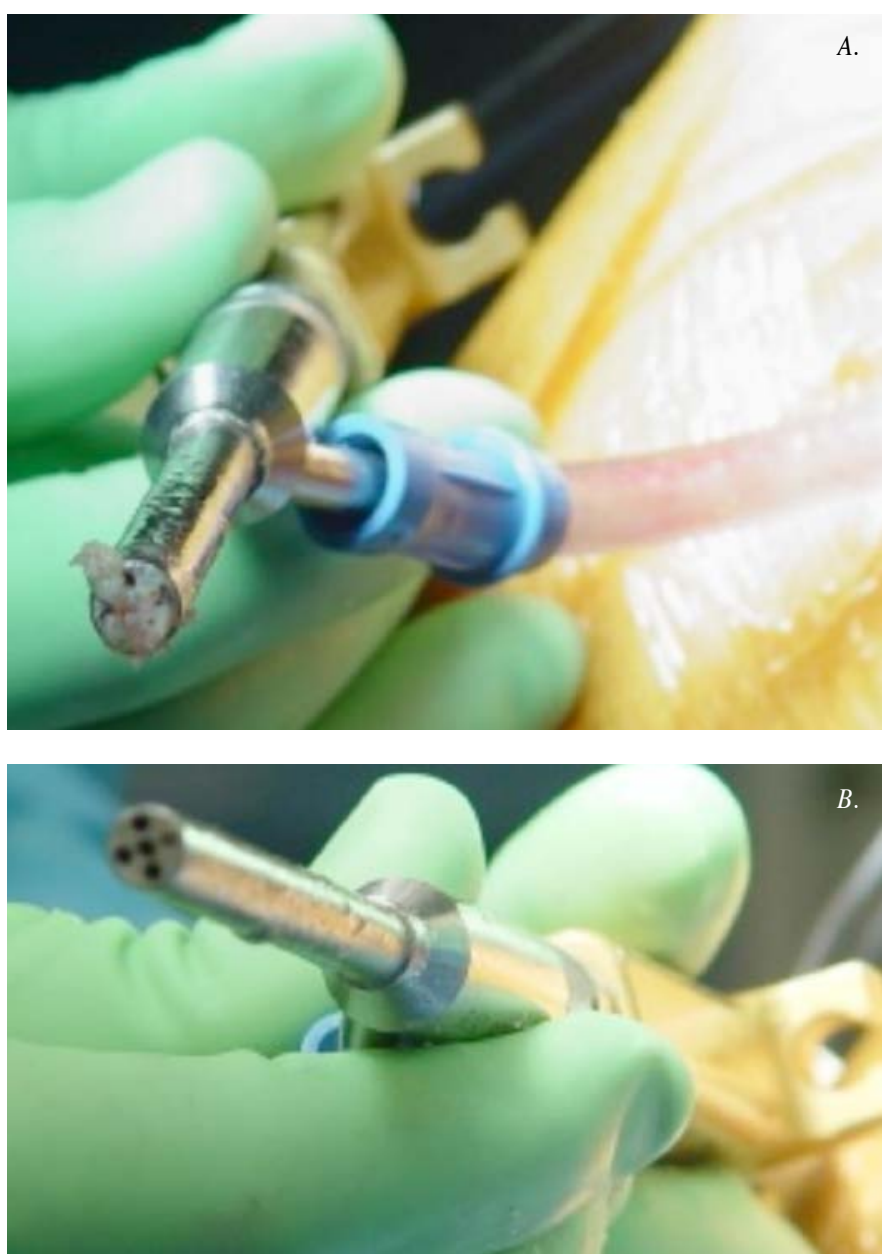

Figure 2. (A) Clogged suction tip; blockage at screen prevents continuous flow of suction. (B) Same suction tip immediately after screen has been cleared by a rapid blast of pressurized medical-grade carbon dioxide gas. 
surgical practice of the author. During the study period, all consecutive patients requiring total knee (TKA) and total hip (THA) arthroplasty were asked to participate. Seventy patients (40 TKA and 30 THA) provided informed consent and were enrolled. Because this study evaluated a specific characteristic during the surgical procedure, the only patient contact was the original recruitment and consent process for the study. Using a computerized randomization scheme, the 70 patients were randomized into one of three study groups: TJA performed with either Super Sucker $(n=17)$, Yankauer $(n=19)$, or the gas-actuated $(n=34)$ suction instrument. Patient characteristics are summarized in Table 1.

The $\mathrm{CO} 2$ gas-actuated suction instrument consists of a hand piece attached to two tube connections, one tube for the standard operating room vacuum suction line, and another tube for a pressure-regulated positive supply of $\mathrm{CO} 2$ gas through the suction tip (Figure 3). Carbon dioxide was the gas of choice as it is delivered sterile and has been used for decades for similar purposes, such as with the FDAcleared CarboJet ${ }^{\circledR}$ lavage system (Kinamed Inc, Camarillo, CA, USA). $[4,5,8,9]$ The CarboJet lavage system was connected to the new suction instrument for the current study. The suction tip includes an inner tube with a connector that attaches to the CarboJet lavage hand piece such that activation releases a jet of $\mathrm{CO} 2$ to the undersurface of the suction tip. The Yankauer, 'Super Sucker', and the gasactuated suction instrument all used the standard vacuum hose tubing that connects to a typical operating room suction canister pulling 45 psi of negative pressure. Outcome measures included: incidence of complete suction loss due to suction instrument obstruction; time lost while unplugging the suction instrument; number of additional suction instruments needed; and a subjective surgeon assessed performance score ( 5 for the highest performance and 1 for the lowest performance).

Statistical analysis. Pilot testing demonstrated that tra- ditional suction instruments become completely obstructed at least once during more than half of TJA cases. It was determined that, at a $95 \%$ confidence level and with $80 \%$ power, a sample size of 14 patients per group were required to detect a statistically significance difference between an instrument that plugs in $60 \%$ of cases versus one that plugs in $10 \%$ of cases. Student's t-tests and analysis of variance

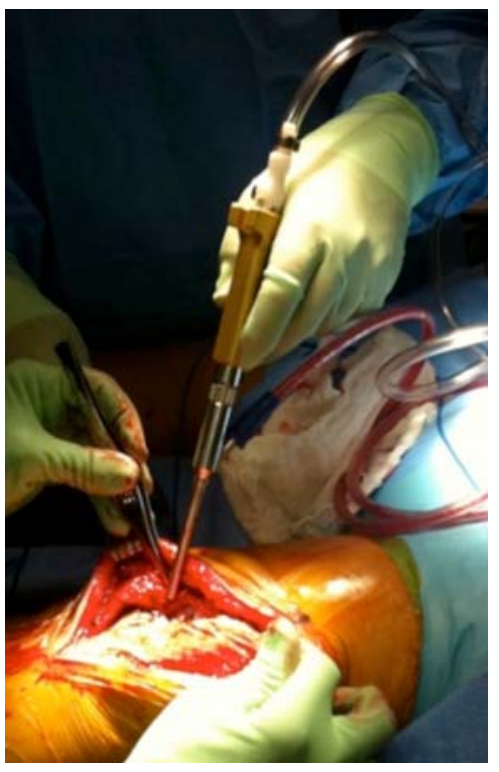

Figure 3. Gas-actuated suction instrument in use during primary TKA.
(ANOVA) tests were used to assess differences in continuous variables (e.g. patient characteristics, time lost due to obstruction) and chi-squared tests were used to compare proportional differences in categorical variables (e.g. gender, presence or not of obstruction). [2] A p-value of 0.05 was considered statistically significant.

\section{Results}

There were no cases in which the gas-actuated suction instrument could not be rapidly cleared of debris. The Super Sucker completely plugged in $71 \%$ of cases, requiring 67 minutes total to unplug (3.9 minutes per case, range 0 to 12 minutes). In four cases, replacement Super Suckers were required to finish the case. The Yankauer completely plugged in $47 \%$ of cases, requiring 52 minutes total to unplug (2.8 minutes per case, range 0 to 10 minutes). In three

Table 1. Patient characteristics.

Height and weight data reported as average \pm standard deviation (range).

\begin{tabular}{|c|c|c|c|c|}
\hline & $\begin{array}{c}\text { Group } 1 \\
\text { (Super Sucker) }\end{array}$ & $\begin{array}{c}\text { Group } 2 \\
\text { (Yankauer) }\end{array}$ & $\begin{array}{c}\text { Group } 3 \\
\text { (Gas-Actuated) }\end{array}$ & Comparing all 3 Groups \\
\hline n (Patients) & $\begin{array}{c}17 \\
(12 \mathrm{TKA}, 5 \text { THA) }\end{array}$ & $\begin{array}{c}19 \\
(9 \text { TKA, } 10 \text { THA) }\end{array}$ & $\begin{array}{c}34 \\
(19 \text { TKA, } 15 \text { THA) }\end{array}$ & \\
\hline Height (inches) & $\begin{array}{c}66 \pm 3 \\
(61 \text { to } 71)\end{array}$ & $\begin{array}{c}67 \pm 5 \\
(60 \text { to } 74)\end{array}$ & $\begin{array}{c}65 \pm 4 \\
(60 \text { to } 72)\end{array}$ & $\begin{array}{l}\text { Not Significant } \\
\quad(p=0.57)\end{array}$ \\
\hline Weight (lbs) & $\begin{array}{c}192 \pm 43 \\
(112 \text { to } 240)\end{array}$ & $\begin{array}{c}191 \pm 56 \\
(76 \text { to } 288)\end{array}$ & $\begin{array}{c}177 \pm 50 \\
(83 \text { to } 281)\end{array}$ & Not Significant $(\mathrm{p}=0.48)$ \\
\hline BMI & $\begin{array}{c}31 \pm 6.5 \\
(20 \text { to } 43)\end{array}$ & $\begin{array}{c}30 \pm 8 \\
(13 \text { to } 47)\end{array}$ & $\begin{array}{c}29 \pm 6.5 \\
(15 \text { to } 40)\end{array}$ & Not Significant $(\mathrm{p}=0.47)$ \\
\hline Age (years) & $\begin{array}{c}72 \pm 9.7 \\
(54 \text { to } 88)\end{array}$ & $\begin{array}{c}70 \pm 11 \\
(49 \text { to } 88)\end{array}$ & $\begin{array}{c}74 \pm 11 \\
(51 \text { to } 100)\end{array}$ & Not Significant $(\mathrm{p}=0.43$ ) \\
\hline Males:Females & $7: 10$ & $7: 12$ & $8: 26$ & Not Significant $(\mathrm{p}>0.19)$ \\
\hline
\end{tabular}


cases, replacement Yankauers were required to finish the case. The average performance score was 2.7 for the Super Sucker, 3.6 for the Yankauer, and 5 for the gas-actuated sucker on a scale of 1 to 5 , with 5 being most favorable. These results, including the statistical analyses, are summarized in Table 2.

\section{Discussion}

This study evaluated a suction instrument in which a screen tip prevents obstruction, and a burst of pressurized carbon dioxide gas clears debris from the tip. The new suction instrument was successful in $100 \%$ of cases, with considerably less time lost compared to the traditional suction instruments. The traditional suction instruments demonstrated a high tendency to plug. The Yankauer suction instrument could be unplugged by inserting a narrow probe, such as a Bovie tip, into its tip to dislodge the obstruction. The Super Sucker plugged more frequently as the screen in the mid-portion of the device captured the debris. The Super Sucker required the most time for unplugging and it was noted that suction was not always restored to the original state. The gas-actuated suction tool actively and rapidly cleared obstructive debris with minimal disruption to the surgical flow.

The primary limitation of this study is the fact that all cases were done by the developer of the gas-actuated suction instrument who had considerable prior experience in developing the screen tip and the methods to easily clear it. One of these methods is related to the finding that debris and viscous fluid, as is often found in the hip joint after a femoral neck fracture, can congeal in the tube of the gasactuated suction instrument if not completely cleared. Experience has shown that occasionally suctioning irrigation fluid will eliminate this plugging. In addition, on occasion collagenous soft tissue will collect on the screen tip surface and cannot be blown away by the $\mathrm{CO} 2$ jet. Because the metal tip functions like a spaghetti strainer, simple brushing of the tip with a finger will dislodge the debris and allow it to be suctioned away. With attention to these details, no examples of complete plugging of the gas-actuated suction instrument were noted in this study.

Clinical studies on actuated suction instruments are rare. The patent literature, however, describes other types of actuated suction instruments. The author has filed several such examples, but all lacked the simplicity and efficiency of the gas-actuated system studied here. Most of these ideas attempt to combine the function of suction and irrigation with a mechanism to redirect flow. Prusmack [11] described a concept developed for spine surgery with a thumb-valve mechanism for activating the flow of air or fluid irrigant into a common neurosurgical sucker conduit and designed a simple stop-cock mechanism to control the suction outflow from this conduit. Unfortunately, the Prusmack idea ignores fluid mechanics as the negative pressure created by the suction outflow will compromise the flow of air into the suction conduit. To counteract this problem, the user of such a system would need to secondarily turn off the stop-cock for suction outflow to create a 'closed' nonsuctioning system. The gas-actuated instrument described in this paper uses the high air inflow created by the Venturi effect of a narrow conduit over the distance of the suction instrument in order to create a blast of $\mathrm{CO} 2$ of sufficient force to dispel debris from its tip. The system is 'open' and the countereffect of suction is minimal at the tip of the instrument. Efficiency is optimized as the entire unplugging maneuver occurs rapidly with activation of the $\mathrm{CO} 2$ gas jet via a trigger valve.

Several surgical techniques may benefit from a more efficient suction instrument. Recent clinical experience has shown the gas-actuated suction tool to be particularly enabling in the settings of tourniquet-free total knee replacement, which continues to gain interest, "small incision" total hip replacement, bipolar hemiarthroplasty, and revision total hip replacement. Tourniquet-less total knee arthroplasty has been shown to reduce the risk of nerve injury, acute phlebothrombosis, and postoperative hematoma compared to cases where a tourniquet is used. $[3,6]$ The gas-actuated suction instrument also functions as an excellent retractor when not in use, which can be advantageous during minimally invasive procedures. Considering the

Table 2. Summary of results.

\begin{tabular}{|c|c|c|c|c|c|}
\hline & $\begin{array}{c}\text { Group 1 } \\
\text { (Super Sucker) }\end{array}$ & $\begin{array}{c}\text { Group } 2 \\
\text { (Yankauer) }\end{array}$ & $\begin{array}{c}\text { Group } 3 \\
\text { (Gas-Actuated) }\end{array}$ & $\begin{array}{l}\text { Comparing } \\
\text { all } 3 \text { Groups }\end{array}$ & $\begin{array}{l}\text { Comparing } \\
\text { Groups } 1 \text { and } 2 \text { only }\end{array}$ \\
\hline n (Patients) & 17 & 19 & 34 & & \\
\hline Obstruction Rate & $71 \%(12 / 17)$ & $47 \%(9 / 19)$ & $0 \%(0 / 34)$ & $\mathrm{p}<0.001$ & Not Significant $(\mathrm{p}=0.16)$ \\
\hline $\begin{array}{l}\text { Average time to } \\
\text { unplug (minutes) }\end{array}$ & $3.9 \pm 3.5(0$ to 12$)$ & $2.8 \pm 3.0(0$ to 10$)$ & 0 & $\mathrm{p}<0.001$ & Not Significant $(\mathrm{p}=0.28)$ \\
\hline
\end{tabular}


nontrivial cost of operating room time $[1,12]$, the gas-actuated system offers the benefit of reduced operative time. In conclusion, the new gas-actuated suction instrument has been shown to be effective for eliminating the problem of clogged surgical suction.

\section{References}

1. Barrack RL, Ruh EL, Williams BM, Ford AD, Foreman K, Nunley, RM (2012) Patient specific cutting blocks are currently of no proven value. JBJS 94$\mathrm{B}(11): 95-99$.

2. Dowrick AS, Tornetta P, Obremskey WT, Dirchl DR, Bhandari M (2012) Practical research methods for orthopaedic surgeons. JBJS 94-A(4):369-374.

3. Fitzgibbons PG, DiGiovanni C, Hares S, Akelman E (2012) Safe tourniquet use: a review of evidence. J Am Acad Orthop Surg 20(5):310-319.

4. Goldstein WM, Gordon A, Goldstein JM, Berland K, Branson J, Sarin VK (2007) Improvement of cement mantle thickness with pressurized carbon dioxide lavage. 20th Annual Meeting of the International Society for Technology in Arthroplasty. Paris, France

5. Higgs A, McTighe T, Samuels L, Banks S, Woodgate I (2008) A radiological comparison of pressurized carbon dioxide lavage. 68th Annual Meeting of the Australian Orthopaedic Association. Tasmania, Australia.
6. Jones RE (2011) Total knee arthroplasty without the use of a tourniquet. Seminars in Arthroplasty 22:176-178.

7. Kuzmick KM, Anspach WE (1984) Surgical suction tip with filter. United States Patent No: 4,468,217.

8. Lassiter TE, Schroeder RA, McDonagh DL, Bolognesi MP, Sarin VK, Monk TG (2010) Intraoperative embolic events during total knee arthroplasty with use of pulsatile saline versus carbon dioxide lavage. 56th Annual Meeting of the Orthopaedic Research Society. New Orleans, LA.

9. McTighe T, Reynolds HM, Matsen FA, Murray WR, Skinner HB, Guevara J, Roche K (1995) The use of carbon dioxide gas for preparation of bony surfaces in cemented total joint arthroplasty. 8th Annual Meeting of the International Society for Technology in Arthroplasty. San Juan, Puerto Rico.

10. Opie JC (2007) Suction hand-piece with variable control off/on valve. United States Patent Application No: 2007/0016136 A1.

11. Prusmack, CJ (2007) Suction irrigation cleaner. United States Patent Application Publication No: US2007/0213667 A1.

12. Watters TS, Mather RC, Browne JA, Berend KR, Lombardi AB, Bolognesi MP (2011) Analysis of proecedure-related costs and proposed benefits of using patient-specific approach in total knee arthroplasty. J Southern Orthopaedic Association 20(2):112-116 